\title{
Capacidade absortiva como propulsora da inovação em empresas incubadas de Santa Catarina
}

\author{
Absorptive capacity as driver of innovation in \\ incubated companies of Santa Catarina
}

\author{
Alessandra Cassol ${ }^{1}$ \\ Jaqueline zapalai ${ }^{2}$ \\ Renato Fabiano Cintra ${ }^{3}$
}

\section{Resumo}

O capital intelectual vem sendo investigado como um recurso estratégico preparado para ser um propulsor da inovação. Desse modo, supõe-se que o capital intelectual e a capacidade absortiva possam ser recursos influenciadores da gestão da inovação nas empresas. Esta pesquisa, por sua vez, tem como finalidade compreender se a capacidade absortiva é capaz de moderar a relação entre o capital intelectual e a inovação em empresas incubadas. Como método, utilizou-se uma pesquisa descritiva com abordagem quantitativa e aplicação de questionário para uma amostra de 88 respondentes gestores de empresas incubadas de Santa Catarina. $\mathrm{Na}$ análise dos dados foi utilizada a técnica modelagem de equações estruturais através do PLS (Partial Least Squares). Os resultados confirmam que o capital intelectual tem influência positiva na inovação das empresas pesquisadas e que a capacidade absortiva apresenta um papel de moderação na relação entre o capital intelectual e a inovação, ou seja, por meio da capacidade absortiva o conhecimento é mais bem aproveitado, contribuindo de forma acentuada para o desenvolvimento de inovações em empresas incubadas. A presente pesquisa tem como contribuição ampliar a discussão e a compreensão sobre a utilização da capacidade absortiva

1 Doutoranda em Administração pela Universidade Nove de Julho/ SP - UNINOVE. Afiliação: UNINOVE e Universidade do Contestado - UNC Brasil. Lattes: http://lattes.cnpq. br/9005547281638334 Email: alessandracassol.adm@gmail.com

2 Graduação pela Universidade do Contestado - UNC. Afiliação: Universidade do Contestado. Brasil. Email: zapalai_jaqueline@hotmail.com

3 Doutorando em Administração na Universidade Nove de Julho/ SP - UNINOVE. Afiliação:UNINOVE. Brasil. Lattes: http://lattes.cnpq.br/6502890498729102 Email: renatocintra@ hotmail.com 
para tornar-se uma propulsora da inovação moderando o uso do capital intelectual existente nas empresas.

Palavras-chave: Capital intelectual. Capacidade absortiva. Inovação. Empresas incubadas.

\section{Abstract}

The intellectual capital has been investigated as a strategic resource prepared to be a driver of innovation. This way, it is assumed that the intellectual capital and the absorptive capacity can be influential resources of innovation management in companies. This research in turn aims to comprehend if absorptive capacity is able to moderate the relation between intellectual capital and innovation in incubated companies. As a method, a descriptive research with a quantitative approach and a questionnaire to a sample of 88 managers respondents of incubated companies in Santa Catarina was used. In the data analysis the technique structural equation modeling through the PLS (Partial Least Squares) was used. The results confirm that the intellectual capital has a positive influence on innovation of the companies surveyed, and that the absorptive capacity has a moderating role in the relation between intellectual capital and innovation. In other words, through the absorptive capacity knowledge is better spent contributing markedly to the development of innovations in incubated companies. This research has as contribution to broaden the discussion and understanding of how to use the absorptive capacity to become a driver of innovation making use of intellectual capital existent in companies.

Keywords: Intellectual Capital. Absorptive Capacity. Innovation. Incubated Companies.

\section{Introdução}

Observa-se uma tendência de competição global, em que as empresas que buscam inovar são as que tendem a alcançar melhores resultados. As empresas que se tornam mais competitivas são as que mostram uma capacidade de resposta rápida às necessidades do mercado/cliente, que são capazes de inovar e conseguem coordenar recursos internos e externos em busca de vantagem competitiva. Dessa forma, o capital intelectual representa um ativo intangível dentro das organizações, o qual está em tudo o que envolve a organização, desde o mercado até um simples processo interno, sendo capaz de 
agregar valor (RODRIGUEZ, 2002). Portanto, torna-se importante que as organizações sejam capazes de reconhecer o valor do capital intelectual e compreender como ele pode contribuir para a promoção da inovação. Tem-se como pressuposto que a capacidade absortiva pode ser um potencializador desta relação, propiciando às empresas um melhor uso do capital intelectual e, consequentemente, da capacidade de inovar, pois, conforme as pesquisas de Lane, Koka e Pathak (2006), a capacidade absortiva pode aumentar a velocidade, frequência e magnitude da inovação nas empresas.

Sendo assim, este estudo busca responder à seguinte questão de pesquisa: A capacidade absortiva é capaz de moderar a relação entre o capital intelectual e a inovação em empresas incubadas? Interpreta-se que a organização que consegue se diferenciar no mercado fazendo uso de suas habilidades internas, aplicando o conhecimento em melhorias de processos, produtos ou serviços, e prospectando a inovação, poderá conseguir se direcionar ao mercado de forma que venha a obter melhores desempenhos e uma vantagem competitiva.

A perspectiva teórica da Knowledge-Based View (KBV), que é derivada da Resource-Based View (RBV), considera e reforça o papel do conhecimento como principal fonte de vantagem competitiva (KOGUT; ZANDER, 1992) e, em termos estratégicos, como o mais importante dos recursos da firma (GRANT, 1996, 2002). Nesse sentido, a organização possui como desafio desenvolver a habilidade de criar um contexto favorável para integrar o conhecimento especializado individual (tácito e explícito) a outros conhecimentos externos e aplicálo no desenvolvimento de novas capacidades (GRANT, 1996, 2002; NODA; BOWER, 1996). Esta integração do conhecimento intrínseco na empresa ao conhecimento adquirido de fontes externas pode ser realizada por meio da capacidade absortiva, a qual pode potencializar a inovação.

Dessa forma, o objetivo desta pesquisa é compreender se a capacidade absortiva possui um papel de moderação na relação entre o capital intelectual e a inovação. Nos últimos anos, pesquisas têm sido 
desenvolvidas buscando compreender como a capacidade absortiva é capaz de ser propulsora da inovação (COHEN; LEVINTHAL, 1990; LANE; KOKA; PATHAK, 2006; LICHTENTHALER; LICHTENTHALER, 2009; MACHADO; FRACASSO, 2012; CASSOL et al., 2014). Nesta pesquisa, busca-se contribuir para estas discussões trazendo maior compreensão a respeito da relação entre a capacidade absortiva das empresas e as práticas de inovação.

A pesquisa possui uma abordagem quantitativa descritiva, em que se realizou um Survey com uma amostra de 88 empresas incubadas de Santa Catarina. Para a análise dos resultados, utilizou-se de técnicas multivariadas, como o modelo de equações estruturais com a utilização do Software Smart PLS. Os resultados confirmam que o capital intelectual tem influência positiva na inovação das empresas pesquisadas e que a capacidade absortiva apresenta um papel de moderação na relação entre o capital intelectual e a inovação, ou seja, por meio da capacidade absortiva o conhecimento é mais bem aproveitado, contribuindo de forma acentuada para o desenvolvimento de inovações em empresas incubadas.

A presente pesquisa tem como contribuição ampliar a discussão e a compreensão sobre a utilização da capacidade absortiva como propulsora da inovação moderando o uso do capital intelectual existente nas empresas. Na seção seguinte, será apresentada a base teórica para a relação entre capital intelectual, capacidade absortiva e inovação. $\mathrm{Na}$ sequência, será abordado o método utilizado neste estudo. Em seguida, os resultados, a discussão e as considerações finais serão descritos.

\section{Revisão de Literatura}

\subsection{Capital intelectual: um recurso intangível nas organizações}

O conceito de capital intelectual tem raízes na área econômica. Foi utilizado pela primeira vez em 1969, por John Kenneth Galbraith, porém, foi Tom Stewart que popularizou o conceito com a publicação de um artigo em 1991(MACHADO, 2014). Portanto, o conceito tornou-se conhecido 
no final dos anos 90, mostrando-se um marco, pois fazia a diferenciação entre os ativos tangíveis e os ativos intangíveis (GOWTORPE, 2009). A teoria pode ser nova, mas, na prática, o capital intelectual já existe há anos, mas a maior parte de sua literatura está voltada à área contábil, pois visa medir recursos e capacidades intangíveis em forma de relatórios (STEFANO et al., 2014). As organizações começaram a buscar possibilidades de registrar e gerenciar seus ativos intangíveis com o objetivo de desenvolver diferenciais competitivos em relação aos seus concorrentes, intensificando o valor da gestão do conhecimento.

Conforme Hand e Lev (2003, p. 305), os "[...] ativos intangíveis referem-se a quaisquer itens não físicos que tenham a habilidade de fornecer futuros benefícios econômicos às organizações." Corroborando, lenciu e Matis (2011) colocam que os ativos intangíveis referem-se aos recursos controlados pela empresa, porém, que não têm natureza física e são capazes de trazer futuros benefícios econômicos à empresa, além de serem legalmente protegidos. Nesta pesquisa, utilizar-se-á do conceito proposto por Stewart (1998), em que o capital intelectual refere-se à soma do conhecimento de todos em uma empresa, o que proporciona vantagem competitiva à organização.

O capital intelectual possui diferentes componentes, porém, todos com definições similares ou complementares. Mais recentemente, lenciu e Matis (2011) apontam que o capital intelectual deve conter três elementos principais: o capital humano, o capital estrutural e o capital relacional. Segundo Gil e Arnosti (2007), o capital humano é o que envolve os conhecimentos e a capacidade de aprendizagem dos colaboradores que constituem a organização. No capital estrutural podemos encontrar: patentes, conceitos, modelos e sistemas de informações computacionais e administrativos, lideranças, decisões, estratégias, culturas e valores. Esses componentes podem ser desenvolvidos tanto interna quanto externamente na organização (GIL; ARNOSTI, 2007). Já o relacionamento da empresa com o público, interno ou externo clientes, financiadores, fornecedores, acionista, entre outros -, constitui o chamado capital relacional (GIL; ARNOSTI, 2007). 
Nesta pesquisa, as dimensões do capital intelectual utilizadas são apresentadas no quadro 1 a seguir:

Quadro 1 - Conceitos das dimensões do capital intelectual

\begin{tabular}{|c|c|c|}
\hline Capital Estrutural & $\begin{array}{c}\text { Capital de Clientes/ } \\
\text { Relacional }\end{array}$ & Capital Humano \\
\hline $\begin{array}{l}\text { Capital estrutural } \\
\text { configura-se como sendo } \\
\text { as ferramentas utilizadas } \\
\text { para transformar o } \\
\text { conhecimento individual } \\
\text { em ativo da organização } \\
\text { (SCHMIDT; SANTOS, } \\
\text { 2002). }\end{array}$ & $\begin{array}{l}\text { Capital relacional abrange } \\
\text { o cliente, o parceiro e a } \\
\text { comunidade. Os parceiros } \\
\text { são: as alianças estratégicas, } \\
\text { relações colaborativas, joint } \\
\text { ventures e associações de } \\
\text { indústria, parcerias com } \\
\text { universidades (KNIGHT, } \\
\text { 1999). }\end{array}$ & $\begin{array}{l}\text { Capital Humano considera- } \\
\text { se como o conhecimento } \\
\text { intrínseco nas pessoas, } \\
\text { estando relacionado à } \\
\text { capacidade, habilidade, } \\
\text { experiência, criatividade e } \\
\text { inovação dos empregados } \\
\text { (EDVINSSON; MALONE, } \\
\text { 1998). }\end{array}$ \\
\hline
\end{tabular}

Fonte: Adaptado de Cassol et al. (2014).

Assim, entende-se que o capital intelectual se torna um recurso relevante às empresas e de difícil imitação e substituição, pois representa os recursos próprios de cada organização. Verifica-se a necessidade das organizações compreenderem quais capacidades seriam necessárias para ganhar e manter a vantagem competitiva (BARNEY, 1991; PRAHALAD; HAMEL, 1990), pois se observa que as capacidades organizacionais baseadas no conhecimento apresentam grande relevância e, se a organização conseguir desenvolver sua capacidade absortiva, ela poderá assimilar este conhecimento existente de forma mais rápida e eficiente, usufruindo-o.

\subsection{Capacidade absortiva: um diferencial competitivo nas empresas}

Os primeiros autores a discutirem o termo capacidade absortiva foram Cohen e Levinthal, em 1989. A capacidade absortiva é a competência que a empresa tem em analisar o valor de novos conhecimentos para então adaptar essas informações e empregálas nela própria. As empresas que investem na capacidade absortiva 
têm como objetivo identificar e aproveitar as novas oportunidades tecnológicas antes dos seus concorrentes (COHEN; LEVINTHAL, 1990).

A capacidade absortiva mantém-se ligada ao estoque de conhecimento que uma empresa dispõe. Esse argumento tem fundamento, pois os conhecimentos acumulados pelos indivíduos tendem a crescer com a capacidade de memorização e com a aquisição de novos conhecimentos. Porém, não se pode relacionar a capacidade absortiva que uma empresa possui com a que seus colaboradores oferecem, elas não se comparam na soma da mesma individualmente (OLIVEIRA; BALESTRIN, 2012). As empresas com níveis mais altos de capacidade absortiva tendem a ser mais impetuosas, assim pesquisando oportunidades atuais no ambiente, buscando melhorar seu desempenho (COHEN; LEVITHAL, 1990). A capacidade absortiva se fundamenta nos níveis de interação intraorganizacional, interorganizacional e de conhecimento científico, como mostra o quadro 2, a seguir.

Quadro 2 - Níveis de interação da capacidade absortiva

\begin{tabular}{|l|l|l|}
\hline Nível de Interação & Base da Interação & Exemplos \\
\hline Intraorganizacional & $\begin{array}{l}\text { Capturar conhecimento dentro } \\
\text { dos limites da empresa e } \\
\text { desenvolver conhecimentos } \\
\text { próprios. }\end{array}$ & $\begin{array}{l}\text { Melhorar processos internos; } \\
\text { desenvolver } \\
\text { competitivos únicos. diferenciais }\end{array}$ \\
\hline Interorganizacional & $\begin{array}{l}\text { Formar parcerias para atingir } \\
\text { objetivos comuns, ou adquirir } \\
\text { conhecimentos por meio de } \\
\text { valor monetário. }\end{array}$ & $\begin{array}{l}\text { Melhorar desempenho junto } \\
\text { com parceiros; minimizar custos } \\
\text { de pesquisa em P\&D; comprar } \\
\text { tecnologias e/ou treinamentos. }\end{array}$ \\
\hline $\begin{array}{l}\text { Conhecimento } \\
\text { Científico }\end{array}$ & $\begin{array}{l}\text { Cooperar com universidades } \\
\text { e institutos públicos, podendo } \\
\text { obter subsídios para pesquisa. }\end{array}$ & $\begin{array}{l}\text { Estágios em diferentes setores } \\
\text { de pesquisa; projetos financiados } \\
\text { em P\&D. }\end{array}$ \\
\hline
\end{tabular}

Fonte: Adaptado de Schmidt (2005).

A proposta de Schmidt (2005) amplia o contexto sugerido pelos demais autores, podendo se tornar de fácil compreensão e aplicação dentro das organizações, assimilando a capacidade absortiva e as práticas de gestão relacionadas ao desenvolvimento do conhecimento. Verifica-se que o conhecimento externo às organizações não beneficia igualmente todas as empresas, ou seja, os benefícios são determinados 
pela capacidade absortiva individual de cada empresa (WANG; HAN, 2011). Entretanto, observa-se que a falta da capacidade absortiva é um dos fatores mais importantes que dificultam a eficácia do compartilhamento de conhecimento (SZULANSKI, 1996), e constitui uma grande barreira para a aquisição de novos conhecimentos e sustentação de vantagens competitivas (LIU, 2012).

Verifica-se que Zahra e George (2002) já afirmavam que a capacidade absortiva pode ser dinâmica e pertencente à criação e utilização do conhecimento, e pode aumentar a habilidade da empresa de obter e manter uma vantagem competitiva, esse será o conceito que dará suporte a esta pesquisa. Ou seja, podem existir diferentes níveis de absorção do conhecimento relacionados aos níveis de desenvolvimento do conhecimento em que a organização se encontra. Dessa forma, os autores propõem que a capacidade absortiva se divida em capacidade absortiva potencial e capacidade absortiva realizada. Na capacidade absortiva potencial tem-se uma bagagem de conhecimento que foi adquirida e assimilada, mas que se encontra em um nível "adormecido", até que exista um real uso para esse conhecimento. A capacidade absortiva realizada preocupa-se com a transformação e aplicação do que foi previamente adquirido, proporcionando uma vantagem competitiva a ser desenvolvida em curto ou médio prazo (ZAHRA; GEORGE, 2002).

A capacidade absortiva é composta por quatro principais dimensões, as quais são divididas entre os dois tipos de capacidade absortiva. A aquisição e assimilação do novo conhecimento são integrantes da capacidade absortiva potencial. A transformação e aplicação (exploitation) compõem a capacidade absortiva realizada. $O$ quadro 3 apresenta as dimensões e os componentes da capacidade absortiva propostos inicialmente por Cohen e Levinthal (1990) e, posteriormente, por Zahra e George (2002) e demais autores citados. 
Quadro 3 - Dimensões da capacidade absortiva

\begin{tabular}{|c|c|c|c|}
\hline Dimensões & Componentes & Definições & Autores \\
\hline \multirow{2}{*}{$\begin{array}{l}\text { Capacidade } \\
\text { Absortiva } \\
\text { Potencial }\end{array}$} & Aquisição & $\begin{array}{l}\text { É a habilidade da empresa } \\
\text { de localizar, identificar, } \\
\text { valorizar e adquirir } \\
\text { conhecimento externo. }\end{array}$ & $\begin{array}{l}\text { Cohen e Levinthal (1990); } \\
\text { Zahra e George (2002); } \\
\text { Lane, Koka e Pathak } \\
\text { (2006); Murovec e Prodan } \\
\text { (2009); Camisón e Fóres } \\
\text { (2010) }\end{array}$ \\
\hline & Assimilação & $\begin{array}{l}\text { São os processos e } \\
\text { rotinas que permitem que } \\
\text { a nova informação ou } \\
\text { conhecimento adquirido } \\
\text { seja analisado, processado, } \\
\text { interpretado, entendido, } \\
\text { internalizado e classificado. }\end{array}$ & $\begin{array}{l}\text { Cohen e Levinthal (1990); } \\
\text { Zahra e George (2002); } \\
\text { Lane, Koka e Pathak } \\
\text { (2006); Torodova e } \\
\text { Durisin (2007); Camisón e } \\
\text { Fóres (2010) }\end{array}$ \\
\hline \multirow[t]{2}{*}{$\begin{array}{l}\text { Capacidade } \\
\text { Absortiva } \\
\text { Realizada }\end{array}$} & Transformação & $\begin{array}{l}\text { Refere-se ao refinamento } \\
\text { do conhecimento } \\
\text { externamente adquirido } \\
\text { para adequá-lo às rotinas } \\
\text { internas, de modo a } \\
\text { facilitar a transferência } \\
\text { e a combinação de } \\
\text { conhecimento prévio com } \\
\text { o novo conhecimento } \\
\text { adquirido ou assimilado. }\end{array}$ & $\begin{array}{l}\text { Cohen e Levinthal (1990); } \\
\text { Stock et al. (2001); } \\
\text { Szulanski (2000); Zahra } \\
\text { e George (2002); Lane, } \\
\text { Koka e Pathak (2006); } \\
\text { Camisón e Fóres (2010) }\end{array}$ \\
\hline & Aplicações & $\begin{array}{l}\text { Rotinas e processos que } \\
\text { criam novas operações, } \\
\text { conhecimentos, } \\
\text { competências, bens e } \\
\text { produtos. }\end{array}$ & $\begin{array}{l}\text { Cohen e Levinthal (1990); } \\
\text { Szulanski (1996; 2000); } \\
\text { Lane e Lubatkin (1998); } \\
\text { Camisón e Fóres (2010) }\end{array}$ \\
\hline
\end{tabular}

Fonte: Adaptado de Morgado e Fleury (2012)

Compreende-se que, para a organização estar em igualdade com o mercado competitivo, é necessário que ela desenvolva a capacidade absortiva tendo em vista suas necessidades e objetivos, não deixando de analisar as competências externas e internas, tornandose assim uma organização capaz de agregar valor. Dessa forma, podemos ainda destacar que a capacidade absortiva tem a função de captar o conhecimento, tanto interno quanto externo, e transformá-lo, proporcionando o desenvolvimento de inovações, ou seja, a criação de novos produtos e serviços que satisfaçam os clientes e sejam capazes de construir um diferencial competitivo. 


\subsection{Inovação: uma necessidade para manter a competitividade}

Schumpeter (1997) propôs, na primeira metade do século $\mathrm{XX}$, algumas formas de inovação: a introdução de um novo bem, a introdução de um novo método de produção, a abertura de um novo mercado, a conquista de uma nova fonte de matéria-prima ou de bem semimanufaturado, e o estabelecimento de uma nova organização de qualquer indústria. $\mathrm{O}$ autor apresenta o contexto em que novas combinações podem ser inovadoras, desde que sejam realmente algo inédito no mercado ou no segmento da firma.

A inovação refere-se ao crescimento em relação ao mercado de negócios e está relacionada às novas ideias, contudo, não se refere somente à abertura de novos mercados. Ela também está relacionada ao aperfeiçoamento dos mercados que já estão amadurecidos (BESSANT; TIDD, 2009). A inovação, abordada de forma mais ampla, pode ser entendida como um processo de busca, descoberta, experimentação, desenvolvimento, imitação e adoção de novos produtos, processos de produção e arranjos organizacionais (DOSI, 1984; DOSI; NELSON; WINTER, 1996). Segundo Leonard e Sensiper (1998), o processo de inovação configura-se como um ritmo de pesquisa e seleção de exploração. Um processo pelo qual um grupo ou indivíduo primeiro cria opções para, em seguida, escolher uma das opções na qual concentrará seus esforços.

O desenvolvimento da inovação não é uma tarefa fácil para as organizações, mas torna-se necessária para aumentar a competitividade. A inovação normalmente engloba riscos e incertezas, pois necessita de recursos muitas vezes escassos, mas o que pode ser realizado são trabalhos em grupo, o que normalmente acontece em empresas de pequeno porte em que esses recursos são mais escassos, assim, trabalhando em conjunto, a chance da inovação acontecer é maior, pois se utiliza de situações para serem testadas (BESSANT et al., 2009).

Segundo Bessant e Tidd (2009), a gestão da inovação está centrada em três fatores principais: 1) a geração de novas ideias, 2) a seleção estratégica destas, a fim de que se opte por investir nas mais 
promissoras e, por fim, 3) a implementação, tornando-a um produto, serviço ou processo acabado e disponível. Para tanto, segundo os autores, o sucesso das inovações depende de dois ingredientes principais: os recursos (pessoas, conhecimento, financeiros, entre outros) e a capacidade da organização em geri-los.

Nessa pesquisa, utilizaremos o conceito de inovação proposto pelo Manual de Oslo (ORGANIZAÇÃO PARA COOPERAÇÃO E DESENVOLVIMENTO ECONÔMICO, 2012) no qual inovação referese à implementação de um produto/serviço novo ou significativamente melhorado. Um novo processo, um novo método de marketing ou um novo método organizacional de práticas de negócios.

A inovação, seguindo os preceitos de Schumpeter (1934, 1997), pode assumir quatro formas: inovação de produto (envolve mudança nas características ou na estrutura dos produtos ou serviços que a empresa oferece), inovação de processo (considera a mudança na forma em que os produtos/serviços são criados e entregues), inovação de posição (trata das mudanças no contexto em que produto/serviços são introduzidos) e inovação de paradigma (refere-se às mudanças nos modelos mentais subjacentes que orientam o que a empresa faz) (BESSANT et al., 2009). Com o objetivo de esclarecer as tipologias da inovação elaborou-se o quadro 4.

Quadro 4 - Tipologias da inovação

\begin{tabular}{|l|l|l|}
\hline Tipologia & Conceitos & Autores \\
\hline $\begin{array}{l}\text { Inovação não } \\
\text { tecnológica }\end{array}$ & $\begin{array}{l}\text { Todas as inovações que não sejam } \\
\text { relacionadas com novas tecnologias ou } \\
\text { alterações destas. }\end{array}$ & OCDE (1997); Manual \\
& $\begin{array}{l}\text { É a implantação/comercialização de } \\
\text { um produto com características de } \\
\text { desempenho aprimoradas, de modo a } \\
\text { fernecer ao consumidor serviços novos } \\
\text { Inovação tecnológica: } \\
\text { Produtos ou Processos } \\
\text { ou aprimorados. }\end{array}$ & \begin{tabular}{l} 
(2005). \\
\hline
\end{tabular} \\
\hline
\end{tabular}




\begin{tabular}{|c|c|c|}
\hline Inovação Administrativa & $\begin{array}{l}\text { Podem ser reconhecidas por modificar } \\
\text { o sistema social das organizações e } \\
\text { promover novas políticas relacionadas } \\
\text { com recrutamento de pessoal, alocação } \\
\text { de recursos e estrutura. }\end{array}$ & \multirow{2}{*}{$\begin{array}{l}\text { Damanpour, Evan } \\
\text { (1984); Damanpour, } \\
\text { Gopalakrish e Nan } \\
\text { (2001). }\end{array}$} \\
\hline Inovação Técnica & $\begin{array}{l}\text { São definidas como mudanças ou } \\
\text { melhorias no desempenho do sistema } \\
\text { técnico e são conectadas com a atividade } \\
\text { principal das organizações. }\end{array}$ & \\
\hline Inovação Revolucionária & $\begin{array}{l}\text { Criação de novos produtos, processos } \\
\text { ou serviços com características não } \\
\text { relacionadas com qualquer padrão } \\
\text { existente, são mais complexos e com } \\
\text { alto nível de incerteza atribuído às suas } \\
\text { especificações. }\end{array}$ & $\begin{array}{l}\text { Tidd, Bessant e Pavitt } \\
\text { (1997); Lynn e Akgun } \\
\text { (1998); Tigre (2006); } \\
\text { Freeman e Soete } \\
\text { (2008); Serra et al. } \\
\text { (2008); Tidd, Bessant } \\
\text { e Pavitt (2008). }\end{array}$ \\
\hline Inovação Aberta & $\begin{array}{l}\text { Utilização de ideias e caminhos } \\
\text { advindos do ambiente externo e interno } \\
\text { nas decisões de desenvolvimento de } \\
\text { inovação com a finalidade de que as } \\
\text { empresas avancem tecnologicamente. }\end{array}$ & \\
\hline Inovação Fechada & $\begin{array}{l}\text { O processo de inovação é considerado } \\
\text { fechado pelo fato de os projetos } \\
\text { (produtos e serviços) entrarem de uma } \\
\text { única forma (por meio da base científica } \\
\text { ou tecnológica) no início do processo, } \\
\text { e saírem apenas na forma de um } \\
\text { resultado, indo em direção ao mercado. } \\
\text { Limita-se em apenas investir e utilizar os } \\
\text { recursos e capacidades internos. }\end{array}$ & $\begin{array}{l}\text { Chesbrough (2006, } \\
\text { 2011); Dahlander e } \\
\text { Gann (2010). }\end{array}$ \\
\hline
\end{tabular}

Fonte: Adaptado de Sanches (2011).

A inovação pode acontecer conforme a orientação da empresa, isto é, seu intuito em utilizar a inovação. No atual mercado competitivo, as empresas necessitam de um diferencial que facilite alcançar uma posição de destaque no mercado. A capacidade de inovação expõe atributos que uma empresa precisa para ajudar na atividade de inovação, os quais proporcionam à empresa a capacidade de aderir com agilidade novos processos e métodos, desenvolver e inserir novos ou melhores produtos, para uma competição mais efetiva em ambientes que se transformam constantemente (BALAN; LINDSAY, 2007). 
Em se tratando de empresas inovadoras, a procura desse diferencial é mais fundamental e necessária (CUNHA, 2005). A inovação normalmente engloba riscos e incertezas, pois necessita de recursos muitas vezes escassos. Uma opção são as redes onde as empresas de pequeno porte trabalham em conjunto, aumentando as oportunidades de desenvolverem inovações (BESSANT et al., 2009). De acordo com Souza et al. (2015), faz-se necessário que as organizações monitorem indicadores com foco não financeiros, como desempenho de mercado junto a clientes, desempenho dos processos internos, e pessoas, tecnologia e inovação. A somatória destes indicadores alavancará o desempenho esperado e criará valor futuro.

\section{Desenvolvimento conceitual e hipótese}

Com base no modelo busca-se compreender, no ambiente empírico, se o capital intelectual influencia positivamente a inovação e se a capacidade absortiva modera esta relação. Desse modo, infere-se que, uma vez que a organização consegue utilizar o conhecimento interno e absorver conhecimentos externos, assimilando e gerando diferentes formas de inovações, um novo conhecimento é criado, potencializando o desenvolvimento de inovações.

Buscando compreender melhor as hipóteses da pesquisa e as relações entre os constructos propôs-se um modelo conceitual, conforme a figura 1. As hipóteses buscam, na teoria, a relação entre os constructos e, na pesquisa empírica, esta comprovação por meio dos testes realizados e dos dados coletados, verificando-se a existência ou não de relações entre os constructos. 


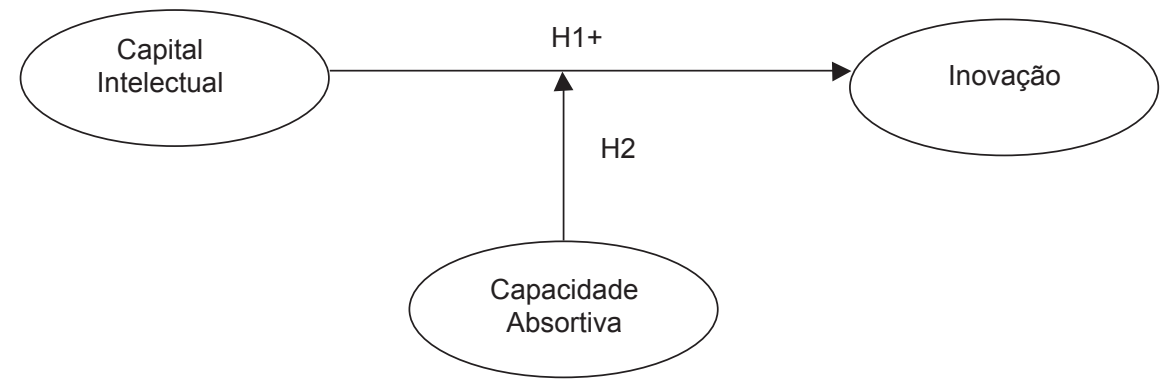

Figura 01 - Modelo de hipóteses

Fonte: Elaborado pelos autores (2014).

A hipótese H1 preconiza a existência de relação entre o constructo capital intelectual e a inovação. Interpreta-se que organizações que possuem ações direcionadas para o desenvolvimento das três dimensões do capital intelectual tornam-se mais propícias à inovação, tornando-se esta uma consequência da gestão estratégica do capital intelectual.

H1: Capital intelectual está positivamente relacionado com a inovação.

Almeida (2008) propõe que o capital intelectual pode tornarse o ponto de partida para a inovação e que os ativos intangíveis de uma organização podem valorizar e fornecer credibilidade, além de determinar a capacidade de inovar e aprender, sendo necessário que as empresas façam uma administração estratégica de seu acervo intelectual. Segundo Santos, Basso e Kimura (2012), os esforços das firmas brasileiras para melhorar sua capacidade de inovar se estruturam em três eixos: capital humano, capital relacional e capital interno ou capital estrutural. Segundo Gracioli et al. (2012), o capital intelectual é responsável por uma porcentagem cada vez maior no desenvolvimento das organizações, criando a maior parte do valor de seus produtos e serviços.

A hipótese $\mathrm{H} 2$ propõe que a capacidade absortiva modera a relação entre capital intelectual e a inovação. Verifica-se que as organizações que possuem a capacidade de adquirir, assimilar, transformar e aplicar 
conhecimentos possuem maior vantagem competitiva em razão da capacidade absortiva se configurar como a habilidade da organização de atribuir valor aos novos conhecimentos, assimilar essas informações e aplicá-las na empresa, e, por meio desta aplicação, pode desenvolverse o processo de inovação.

H2: A capacidade absortiva modera a relação entre o capital intelectual e inovação.

Liu (2012) sugere que, por meio da capacidade absortiva, uma organização consegue lidar com maior rapidez com novos projetos, distribuindo com mais facilidade o pessoal nas equipes, assim minimizando lacunas de conhecimento entre equipes e organizações, e potencializando o conhecimento já existente para desenvolver a inovação. Machado e Fracasso (2012) propõem em um ensaio teórico hipóteses que buscam compreender a relação entre o capital intelectual, capacidade absortiva e inovação. Os autores pressupõem que diferentes recursos internos podem influenciar de forma diferente as dimensões da capacidade absortiva, e, posteriormente, podem levar a resultados diferentes de inovação e desempenho. Flatten et al. (2011) sugerem que o conhecimento organizacional necessita ser compartilhado e potencializado em um processo dinâmico para que, entre outros resultados, possa conduzir à geração de inovações organizacionais. Dessa forma, a H2 propõe que, por meio da moderação da capacidade absortiva, o capital intelectual possa contribuir no desenvolvimento de inovações em empresas incubadas.

\section{Método}

\subsection{Abordagem metodológica}

Neste trabalho, utilizou-se a abordagem quantitativa descritiva, que têm como objetivo a descrição das características de determinada população, podendo ser elaborada também com a finalidade de identificar possíveis relações entre variáveis, como é a proposta deste estudo. A coleta de dados aconteceu por meio de Survey (ou levantamento) 
realizado em empresas incubadas de Santa Catarina. A pesquisa do ponto de vista temporal é de corte transversal.

\subsection{População e amostra}

A população corresponde a empresas incubadas de Santa Catarina, que se caracterizam como um empreendimento que está passando pela incubadora, em que recebe o suporte para se desenvolver (ASSOCIAÇÃO NACIONAL DE ENTIDADES PROMOTORAS DE EMPREENDIMENTOS DE TECNOLOGIAS AVANÇADAS, 2002). Em Santa Catariana existem 28 incubadoras, com 322 empresas incubadas e graduadas, que representam a amostra desta pesquisa (ANPROTEC, 2011). A população da pesquisa é composta por empresas incubadas e graduadas que atuam nas áreas de comércio, consultoria ambiental, educação, indústria/automação, serviços/comércio, tecnologia/indústria e tecnologia/serviços.

Contudo, para verificar adequadamente o número da amostra necessária para a pesquisa, realizou-se o cálculo do tamanho da amostra no Software $G^{*}$ Power (FAUL et al., 2009) um software especializado em cálculos de amostra de alta confiabilidade. Para o cálculo (a priori antes de coletar dados), deve-se observar que há dois parâmetros: o poder do teste (Power = 1 - $\beta$ erro prob. II) e o tamanho do efeito (f2). Cohen (1998), assim como Hair et al. (2014), recomenda o uso do poder como 0,80 e f2 mediano $=0,15$. Sendo assim, o número de amostra mínima necessária para a pesquisa é de 43 participantes. Segundo Rigle, Silva e Bido (2014), para se ter um modelo mais consistente, é interessante usar o dobro ou o triplo desse valor. Nesta pesquisa, a amostra utilizada foi de 88 participantes, sendo todos gestores de empresas incubadas.

\subsection{Coleta e análise dos dados}

Para coleta dos dados, utilizou-se o questionário validado na pesquisa de Cassol et al. (2014), o qual foi utilizado para compreender a relação entre capital intelectual, capacidade absortiva e inovação. Optou- 
se por utilizar esse questionário por já se encontrar validado. Como o questionário havia sido aplicado em uma empresa com características distintas (empresa de papel e celulose) das empresas pesquisadas neste artigo, com o intuito de compreender quais corresponderiam à realidade das empresas incubadas, utilizaram-se todas as variáveis originais da pesquisa.

O questionário possui questões fechadas em escala de multi-itens (escala de Likert 5 pontos). As variáveis e as medidas do constructo capital intelectual foram investigadas por meio das dimensões capital humano, estrutural e relacional, construídas a partir da adaptação do instrumento de pesquisa original de Gracioli et al. (2012). Assim, o constructo possui três dimensões: a primeira dimensão, capital humano, é composta por nove variáveis; a segunda dimensão, capital estrutural, é composta também por nove variáveis, e a terceira, o capital relacional, possui seis variáveis. As variáveis e as medidas do constructo capacidade absortiva foram investigadas por meio das dimensões da capacidade absortiva potencial e realizadas as duas com seis variáveis para cada dimensão. As variáveis foram construídas originalmente a partir do instrumento de pesquisa de Camisón e Forés (2010). As variáveis e as medidas do constructo inovação foram pesquisadas por meio das dimensões inovação de produto, processo, marketing e organizacional. As variáveis foram construídas a partir do instrumento de pesquisa original de Stoeckicht (2012), em que existem nove variáveis para a mensuração de inovação.

O questionário foi enviado via Google forms por e-mail para 322 empresas incubadas de Santa Catarina e, após alguns dias, foi realizado contato via telefone com os gestores das incubadoras para que contribuíssem na divulgação da pesquisa. Encaminhamos o e-mail novamente para toda a amostra. A pesquisa foi realizada no período entre agosto de 2014 e novembro de 2014.

Para a análise dos dados, utilizou-se o Software SPSS, desenvolvendo uma análise descritiva para compreender o perfil das empresas respondentes. Posteriormente, utilizou-se a técnica 
multivariada de dados para compreensão das variáveis pesquisadas, que se refere a métodos estatísticos que, ao mesmo tempo, analisam múltiplas medições sobre cada indivíduo ou objeto de pesquisa (HAIR, 2005). Utilizou-se a modelagem de equações estruturais, uma técnica que combina aspectos na regressão múltipla com análise fatorial (HAIR et al. 2005). Utilizou-se o Software Smart PLS, que utiliza o método de mínimos quadrados parciais e busca atender situações muito frequentes em pesquisa em Ciências Sociais Aplicadas, que se deparam com "poucos" dado, modelos com suporte teórico menos consagrado ou ainda pouco explorados (RIGLE; SILVA; BIDO, 2014), como é o caso desta pesquisa. Nessas situações, são recomendadas as modelagens de equações estruturais baseadas em variância (VB-SEM) ou modelos de estimação de ajuste de mínimos quadrados parciais (partial least square - PLS) (HAIR et al., 2014).

\section{Apresentação e discussão dos resultados}

A primeira avaliação realizada com os dados da pesquisa foi o teste de normalidade. A avaliação de normalidade foi realizada por meio do teste de Kolmogorov-Smirnov, sendo a amostra utilizada de 88 respondentes (maior de 50). O segundo teste realizado foi KaiserMeyer-Olkin (KMO), que deve variar entre 0 e 1, de forma que quanto maior o KMO, maior será a correlação entre as variáveis e maior será a qualidade da Análise Fatorial. O teste $\mathrm{KMO}$ de todas as variáveis apresentou um valor de 0,881, sendo considerado bom, conforme Friel (2009). O teste de Bartlett também foi realizado. Ele deve apresentar valor $p<0,05$ para apresentar correlação entre as variáveis. Neste estudo, o valor observado é de $p<0,000$.

A confiabilidade e validade convergente foram avaliadas por meio da consistência interna dos constructos utilizando o Alfa de Cronbach e a Confiabilidade Composta (CC) de cada constructo. Os dados desta pesquisa apresentaram alfa de Cronbach adequados para todos os constructos, sendo: capacidade absortiva com $\alpha=$ 0,869 , capital intelectual com $\alpha=0,883$ e inovação com $\alpha=0,900$. A 
confiabilidade composta deve apresentar valores superiores a 0,6 para ser considerada aceitável (NUNNALLY; BERNSTEIN, 1994). Nesta pesquisa, os dados representaram as seguintes CC para os constructos: capacidade absortiva $=0,902$, capital intelectual $=0,907$ e inovação $=$ 0,921 , portanto, foram todos aceitáveis. Para obter um grau de validade convergente elevado é necessário que o valor de AVE seja de 0,50 ou maior, e os dados obtidos representaram os seguintes valores de AVE para cada constructo: capacidade absortiva $=0,606$, capital intelectual $=$ 0,550 e inovação $=0,627$, ou seja, foram todos aceitáveis.

Observa-se, na tabela 1 , a relevância preditiva $\left(\mathrm{Q}^{2}\right)$, que analisa a precisão do modelo ajustado e tem como critério de avaliação valores maiores que zero (HAIR et al., 2014). Observa-se também o tamanho do efeito $\left(\mathrm{f}^{2}\right)$ baseado no valor que é obtido pela inclusão ou exclusão dos constructos, em que valores entre 0.02 e 0.15 são considerados pequenos; os valores entre 0.15 e 0.35 são médios e os valores acima de 0.35 são grandes (HAIR et al., 2014). Portanto, os valores da relevância preditiva $\left(\mathrm{Q}^{2}\right)$ apresentaram-se maiores que zero e o tamanho do efeito $\left(\mathrm{f}^{2}\right)$ de cada constructo representa grande relevância.

Tabela 1 - Relevância Preditiva $\left(Q^{2}\right)$ e Tamanho do Efeito $\left(f^{2}\right)$ dos construtos

\begin{tabular}{lcc}
\hline \multicolumn{1}{c}{ Dimensões } & $\mathbf{Q}^{\mathbf{2}}$ & $\mathbf{f}^{\mathbf{2}}$ \\
\hline Capacidade Absortiva & 0,397056 & 0,450392 \\
\hline Capital Intelectual & 0,411865 & 0,411865 \\
\hline Inovação & 0,351711 & 0,495804 \\
\hline
\end{tabular}

Fonte: Dados da pesquisa, 2014.

\subsection{Testes de hipóteses}

Uma vez concluída a avaliação da qualidade de ajuste do modelo, deu-se continuidade com a interpretação dos coeficientes de caminho, os quais são interpretados pelos betas $(\beta)$ das regressões lineares simples ou ordinárias, e pelo valor de T. Na tabela 2, apresenta-se o coeficiente de caminho do modelo estrutural PLS, o qual também pode ser interpretado como coeficientes beta- $\beta$ (coeficientes de regressão 
padronizados) de mínimos quadrados, que podem ser utilizados para uma comparação direta entre coeficientes e seus poderes relativos de explicação da variável dependente (HAIR et al., 2005).

Os coeficientes de caminho indicam quanto um constructo se relaciona com outro. Observa-se que os constructos apresentaram relação positiva em relação ao valor de $\beta$. Segundo Hair et al. (2014), valores variam de $-1,0$ a $+1,0$, sendo que valores próximos de +1.0 indicam relação positiva muito forte entre dois constructos. Logo, valores próximos de $-1,0$ indicam relação negativa ou baixa entre dois constructos. Próximos de zero indicam relações fracas (HAIR et al., 2014).

Tabela 2 - Parâmetros da estrutura quantitativa da pesquisa

\begin{tabular}{l|c|c|c}
\hline Hipóteses & $\beta$ & Valor de T & Situação \\
\hline $\begin{array}{l}\text { H1 - Capital intelectual está positivamente relacionado } \\
\text { com a inovação. }\end{array}$ & 0,39 & 2,977 & Suportada \\
\hline
\end{tabular}

Fonte: dados da pesquisa, 2014.

Observa-se, na tabela 2, a relação entre os constructos e os valores de $\beta$. A relação entre capital intelectual e inovação apresentou um valor positivo, porém não muito significante. No entanto, para que o Beta seja aceito, deve-se testar a relação causal entre os dois constructos e verificar se é significante ou não. Assim, utilizou-se o teste t de Student, em que valores acima de 1,96 são considerados significantes a $5 \%$ ou 0,05 , isto é, os constructos são relacionados (HAIR et al., 2005). Conforme observado na tabela anterior, o teste $t$ apresenta-se significante. 


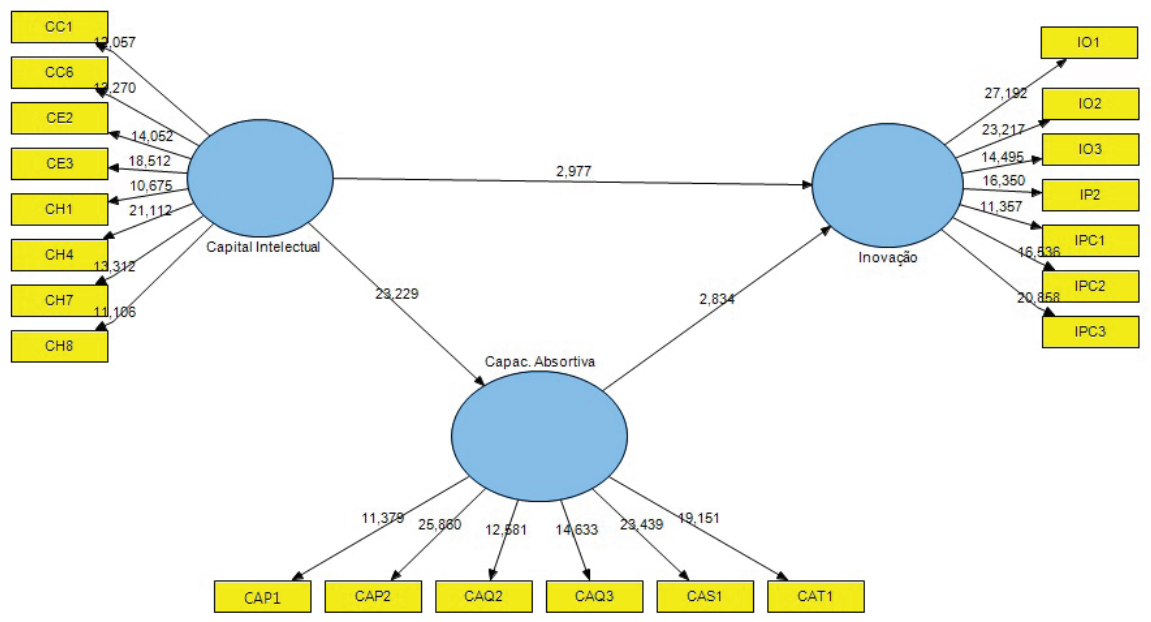

Figura 2 - Estrutura de análise t de caminho.

Fonte: Dados da pesquisa, 2014.

Para tanto, observa-se que todos os valores que foram testados em relação de causa entre os constructos oferecem índices dentro dos parâmetros propostos por Hair et al. (2005), ou seja, suporta-se a hipótese H1. Após esse resultado, buscou-se entender se a capacidade absortiva seria moderadora da relação entre o capital intelectual e inovação. Uma variável moderadora refere-se a um fator ou fenômeno que pode apresentar condição ou ser um fator determinante para que ocasione um resultado, efeito ou consequência (MARCONI; LAKATOS, 2010). Baron e Kenny (1986) definem uma variável moderadora como uma variável qualitativa ou quantitativa que afeta a direção ou a força da relação entre a variável independente (VI) e a variável dependente (VD). Então, para diferentes valores da variável moderadora, a forma, a força ou o sinal pode variar. Nesta pesquisa, buscou-se por uma relação positiva de moderação.

Para tanto, realizou-se o teste no Software Smart PLS, que apresentou um valor de 0.339. Observa-se que capacidade absortiva modera a relação entre capital intelectual e inovação, porém com o efeito 
razoável $(0,339)$, ou seja, após a moderação os resultados melhoraram entre as variáveis. Dessa forma, confirma-se a hipótese H2 desta pesquisa, conforme figura 3 .

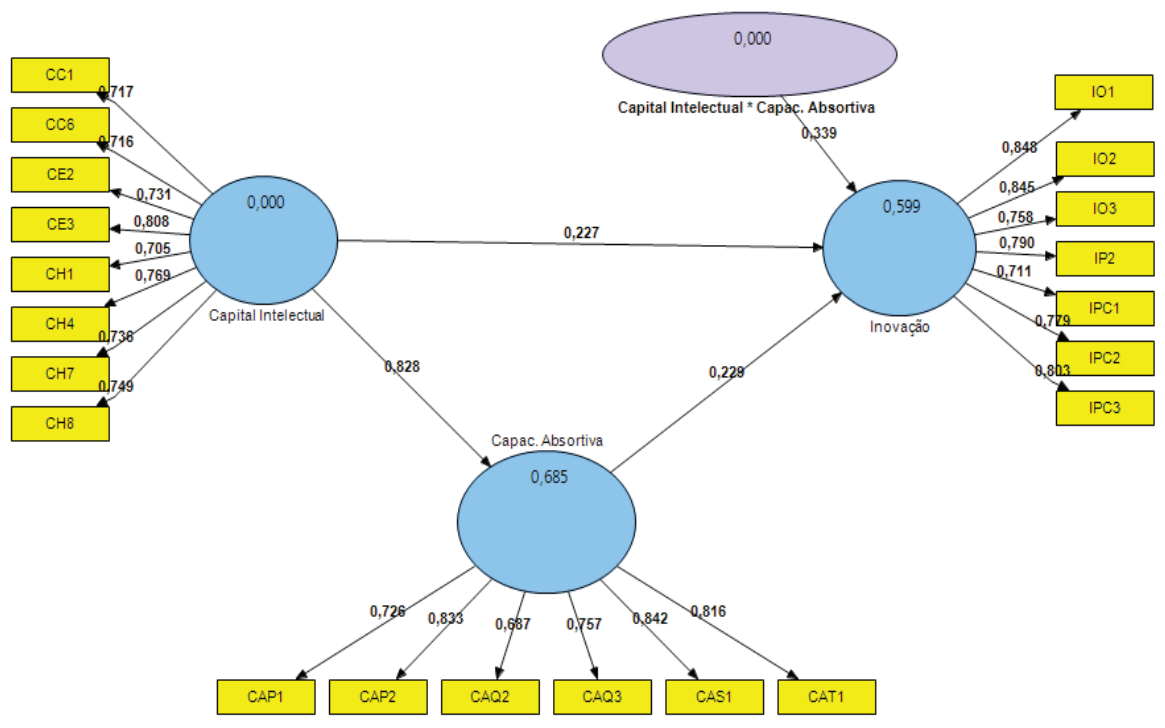

Figura 3 - Capacidade absortiva modera a relação entre capital intelectual e inovação

Fonte: Dados da pesquisa, 2014.

Após os testes estatísticos, realizou-se a análise das hipóteses propostas nesta pesquisa, conforme apresentado na próxima seção.

\section{Discussão dos resultados}

Após concluir os testes estatísticos, buscaram-se apresentar as hipóteses da pesquisa e suas relações com a teoria e resultados de outras pesquisas. As duas hipóteses propostas foram comprovadas, conforme observado no quadro 5. 
Quadro 5 - Situação das hipóteses

\begin{tabular}{|l|l|l|}
\hline \multicolumn{2}{|l|}{ Hipótese } & Situação \\
\hline H1 & Capital intelectual está positivamente relacionado com a inovação. & Suportada \\
\hline H2 & $\begin{array}{l}\text { A capacidade absortiva modera a relação entre o capital intelectual } \\
\text { e inovação. }\end{array}$ & Suportada \\
\hline
\end{tabular}

Fonte: Dados da pesquisa 2014.

A primeira hipótese preconiza a relação entre capital intelectual e inovação. Infere-se que organizações que possuem ações direcionadas para o desenvolvimento das três dimensões do capital intelectual tornam-se mais propícias à inovação, tornando-se esta uma consequência da gestão efetiva do capital intelectual. Observa-se, nas empresas incubadas, que o capital intelectual possui influência positiva sobre a inovação. Infere-se, nesse contexto, que esta relação positiva pode possuir ligação com o aumento dos esforços dos gestores para o desenvolvimento do capital intelectual, além de uma compreensão de que o capital intelectual da organização pode se tornar um diferencial competitivo e um potencializador da inovação.

Essa relação positiva entre o capital intelectual e a inovação também foi constatada por López-Nicolás e Meroño-Cerdán (2011), que verificaram, a partir de uma pesquisa conduzida em 310 empresas espanholas, que as práticas de gestão do capital intelectual têm influência significativa sobre a capacidade de inovação e o desempenho dessas empresas. Segundo Finger (2004), a gestão integrada dos fatores tangíveis e intangíveis está fundamentada no convívio entre a estrutura, processo dos conhecimentos internos ou externos e a rede de relacionamento, que foca na identificação e integração do conhecimento, selecionando o que é mais relevante e usando da melhor forma para gerar valor e retorno à empresa. Sendo assim, infere-se que o desenvolvimento da capacidade absortiva pode propiciar à empresa o aperfeiçoamento dos recursos e o crescimento do recurso capital intelectual. 
Segundo Almeida (2008), o capital intelectual pode se tornar um ponto de partida para a inovação, os ativos intangíveis podem valorizar e fornecer credibilidade em uma organização, com isso designar a capacidade de inovar e aprender, sendo necessário, assim, que as organizações administrem seu acervo intelectual. Com os dados obtidos na pesquisa, pode-se verificar que o capital intelectual é propulsor da inovação, ou seja, o capital intelectual torna-se a base para que as organizações desenvolvam a capacidade de inovar. No entanto, uma organização é inovadora quando busca desenvolver seu capital intelectual tendo como consequência o capital humano, ou seja, buscando atrair e classificar colaboradores novos e reter os talentos que já existem na organização, contribuindo para as competências organizacionais e na criação de inovações (AMORIM; SILVA, 2012). Na pesquisa, constatouse que as empresas incubadas, para gerarem inovações, necessitam que o capital intelectual seja desenvolvido, tornando-se, assim, necessário que as organizações desenvolvam o capital humano incentivando que a inovação seja gerada.

Corroborando com isso, Santos, Basso e Kimura (2012) constataram em sua pesquisa, realizada em 230 indústrias brasileiras, que os esforços das firmas para melhorar sua capacidade de inovar se estruturam em três eixos: capital humano, capital relacional e capital interno (abordado como estrutural neste estudo). A pesquisa dos autores apontou que a capacidade de inovar das firmas no Brasil depende mais do capital relacional, fato que também se comprovou neste estudo de caso, em que se observa uma relação maior entre o capital relacional e a inovação.

Na hipótese 2, buscou-se compreender se a capacidade absortiva funciona como moderadora na relação entre o capital intelectual e a inovação, a mesma se confirmou. Compreende-se que, para as empresas incubadas, a capacidade absortiva pode influenciar no desenvolvimento de inovação por meio do capital intelectual. Segundo Cunha (2005), as empresas consideradas inovadoras possuem práticas gerenciais criadas internamente ou simplesmente absorvidas de outras empresas, que contribuíram para a capacidade de inovação. Assim como na teoria, 
a pesquisa comprovou que a capacidade absortiva possui uma relação moderadora entre o capital intelectual e a inovação nas empresas incubadas, pôde-se observar que as organizações conseguem obter novas informações e transmitir para suas rotinas internas por meio da capacidade absortiva.

Zahra e George (2002) supõem que a capacidade absortiva pode ser dinâmica e pertencente à criação e utilização do conhecimento, e, ainda, aumentar a habilidade da empresa de obter e manter uma vantagem competitiva. Assim, podem existir diferentes níveis de absorção do conhecimento relacionados aos níveis de desenvolvimento do conhecimento em que a organização se encontra. Os dados da pesquisa comprovam que a capacidade absortiva possui influência para que as organizações consigam captar e criar o conhecimento, possibilitando que o capital humano se desenvolva no sentido de promover a geração do conhecimento.

Infere-se, nesse contexto, que é necessário que a capacidade absortiva seja aprimorada e aplicada nas rotinas organizacionais das empresas, para que o capital intelectual possa manter-se ativo e em desenvolvimento dentro da organização, potencializando a inovação. Assim, esse pode ser o diferencial competitivo no ambiente de empresas inovadoras.

\section{Considerações finais}

A presente pesquisa propôs compreender se a capacidade absortiva possui um papel de moderação na relação entre o capital intelectual e a inovação em empresas incubadas de Santa Catarina. Para responder ao objetivo da pesquisa, foram propostas duas hipóteses de pesquisa as quais se confirmaram por meio da análise dos dados quantitativos. Em relação às dimensões do capital intelectual nas empresas, constatouse que as empresas desenvolvem muito mais o capital humano do que o capital relacional e estrutural. As práticas relacionadas ao capital intelectual evidenciadas nas empresas incubadas foram: as sugestões dos colaboradores são implantadas; os colaboradores participam 
das decisões da empresa; o nível de escolaridade/graduação dos colaboradores é alto e os custos com treinamento são elevados.

Verificou-se que as empresas desenvolvem sua capacidade absortiva como diferencial para seu desenvolvimento no mercado. As práticas relacionadas à capacidade absortiva evidenciadas na pesquisa foram: as empresas desenvolvem a capacidade de utilizar e explorar novos conhecimentos no trabalho e responder rapidamente às mudanças do ambiente; existe alto grau de aplicação de conhecimentos e experiência adquirida nos campos tecnológicos e de negócios; existe a frequência e cooperação com as organizações de P\&D - universidades, escolas de negócios e institutos tecnológicos; as empresas atuam como um membro ou patrocinador da criação de conhecimento e inovações; as empresas possuem a capacidade de assimilar novas tecnologias e inovações que são úteis ou têm potencial comprovado; e as empresas possuem capacidade de utilizar as tecnologias de informação, a fim de melhorar o fluxo de informações, desenvolver a partilha efetiva de conhecimentos e fomentar a comunicação entre os membros da empresa.

No que se refere à inovação, verificou-se as seguintes práticas: as competências estratégicas para a inovação, visando à sustentabilidade do negócio e vantagem competitiva futura, são desenvolvidas; existe a promoção de uma cultura organizacional voltada para a inovação; as empresas promovem o comportamento empreendedor e inovador em suas diversas unidades/áreas/departamentos; as empresas desenvolvem melhorias nos produtos existentes; as empresas desenvolvem novos métodos de produção; as empresas melhoram os seus atuais métodos de produção; as empresas buscam a aplicação de novas tecnologias em seus sistemas produção.

Sendo assim, a pesquisa apresentou como pressuposto que a capacidade absortiva pode ser propulsor da inovação. Verificouse que o capital intelectual é propulsor da inovação e possui forte relação com a capacidade absortiva, assim como se observou a relação entre capacidade absortiva e inovação. Dessa forma, infere- 
se que organizações que promovam práticas de desenvolvimento da capacidade absortiva podem potencializar o capital intelectual e criar um ambiente propício para inovação.

Como sugestão para pesquisas futuras, sugere-se a aplicação do modelo proposto a uma amostra maior, por exemplo, em nível estadual ou até mesmo nacional, buscando compreender se empresas de setores dinâmicos, como as incubadas, possuem ações estratégicas direcionadas para o desenvolvimento do capital intelectual e da inovação. Sugerese também que as práticas organizacionais evidenciadas na pesquisa sejam foco de futuras pesquisas buscando compreender a relação entre as práticas de gestão e a promoção da inovação.

A presente pesquisa traz como contribuição empírica que a capacidade absortiva atua como moderadora da relação entre o capital intelectual e a inovação em empresas incubadas, sendo capaz de potencializar a inovação. O estudo apresentou a presença da relação entre o constructo capital intelectual e inovação, disponibilizando para observação as práticas de gestão que são capazes de impulsionar a inovação nas empresas. A pesquisa teve a intenção de contribuir num campo pouco explorado, tanto teórica quanto empiricamente, assim proporcionando a visualização de novos caminhos para pesquisa em relação à inovação.

\section{Referências}

ALMEIDA, P. Inovação sem inteligência é apenas criatividade sem objetivo. Serviço Brasileiro de Apoio às Micro e Pequenas Empresas (Sebrae), 2008. Disponível em: <http://www.sebrae-sc.com.br/newart/ default.asp?materia=16503>. Acesso em: 24 mar. 2013.

AMORIM, T. N. G. F.; SILVA, L. B. Gestão estratégica de pessoas e inovação: uma parceria essencial. RAUnP - Revista Eletrônica do Mestrado Profissional em Administração da Universidade Potiguar, Natal/RN, ano IV, n. 1, art. 3, p. 33-42, out. 2011/mar. 2012. 
ANDRADE, M. M. Como preparar trabalhos para cursos de pós graduação. 4. ed. São Paulo: Atlas, 2001.

ANDRADE, M. M. Pesquisa científica: noções introdutórias. In: Introdução à metodologia do trabalho científico: elaboração de trabalhos na graduação. 6. ed. São Paulo: Atlas, 2003. Cap. 10, p. 121-127.

ASSOCIAÇÃO NACIONAL DE ENTIDADES PROMOTORAS DE EMPREENDIMENTOS INOVADORES. Anprotec. Disponível em: $<$ http://anprotec.org.br/site/pt/incubadoras-e-parques/>..Acesso em: 31 out. 2014.

BALAN, P; LINDSAY, N. Developing innovation capability measures for the services sector: an exploratory study. Melbourne, Australia: Australian Graduate School of Entrepreneurship Research Report, 2007.

BARNEY, J. B. Firm resources and sustained competitive advantage. Journal of Management, [S.I], v. 17, n. 1, p. 99-120, Mar. 1991.

BARON, R. M.; KENNY, D. A. The moderator-mediator variable distinction in social psychological research: conceptual, strategic, and statistical considerations. Journal of Personality and Social Psychology, Washington, v. 51, n. 6, p. 1173-1182, Dec. 1986.

BESSANT, J.; TIDD, J. Inovação e empreendedorismo. São Paulo: Bookman, 2009.

BESSANT, J.; TIDD, J.; PAVITT, K. Gestão da Inovação. 3. ed. São Paulo: Bookman, 2005.

CAMISÓN, C.; FORÉS, B. Knowledge absorptive capacity: new insights for its conceptualization and measurement. Journal of Business Research, [S.I], v. 63, n. 7, p. 707-715, jul. 2010.

CASSOL, A. et al. Capital Intelectual e Capacidade absortiva como Propulsores da Inovação: Estudo de Caso no Setor de Papel e Papelão Ondulado. In: ENCONTRO ANUAL DA ANPAD, 38, 214. Rio de Janeiro. Anais..., Rio de Janeiro: EnANPAD, 2014. p. 1-16. 
COHEN, W. M.; LEVINTHAL, D. A. Innovation and learning: the two faces of R\&D. The Economic Journal, [S.I].v. 99, n. 397, p. 569-596, Sep. 1989.

COHEN, W. M. et al. Absorptive Capacity: A New Perspective on Learning and Innovation. Administrative Science Quarterly, [S.I]. v. 35, n. 1, p. 128-152, mar. 1990.

CUNHA, N. C. V. As práticas gerenciais e suas contribuições para a capacidade de inovação em empresas inovadoras. 2005. 156f. Tese (Doutorado em Administração) - Faculdade de Economia, Administração e Contabilidade da Universidade de São Paulo, 2005.

DOSI, G.; NELSON, R.; WINTER, S.. The nature and dynamics of organizational capabilities. Oxford, Inglaterra: Oxford University Press, 2000.

EDVINSSON, L.; MALONE, M. S. Capital intelectual: descobrindo o valor real de sua empresa pela identificação se seus valores internos. São Paulo: Makron Books, 1998.

FAUL, F. et al. Statistical power analyses using $G^{*}$ Power 3.1: Tests for correlation and regression analyses. Behavior Research Methods, [S.I], v. 41, n.4, p. 1149-1160, Nov. 2009.

FINGER, E. Considerando os intangíveis: Brasil e BNDES. 2004. 155f. Dissertação (Mestrado em Ciências em Engenharia de Produção) - Universidade Federal do Rio de Janeiro, Rio de Janeiro, 2004.

FLATTEN, T. C. et al. A measure of absorptive capacity: scale development and validation. European Management Journal, [S.I], n. 29, n. 2, p. 98-116, Apr. 2011.

GIL, A. L.; ARNOSTI, C. M. Balanço intelectual: a estratégia com projetos de mudanças e o reconhecimento dos talentos humanos. São Paulo: Saraiva, 2007.

GRACIOLI, C. et al. Capital intelectual: uma ferramenta inovadora na busca por vantagens competitivas. Revista de Administração e Inovação, São Paulo, v. 9, n. 4, p. 96-120, out./dez. 2012. 
GRANT, R. M. Toward a knowledge-based theory of the firm. Strategic Management Journal, [S.I], v. 17, n.52, p. 109-122, Winter 1996.

GRANT, R. M. The knowledge-based view of the firm. In: CHOO, Chun Wei; BONTIS, Nick. The strategic management of intellectual capital and organizational knowledge. Oxford, Inglaterra: Oxford University Press, 2002. p. 133-148.

HAIR, J. F. et al. A primer on partial least squares structural equation modeling (plssem). Los Angeles: SAGE, 2014.

HAIR JÚNIOR, J. F. et al. Fundamentos de métodos de pesquisa em administração. Porto Alegre: Bookman, 2005.

HAIR JÚNIOR, J. F. et al. Análise Multivariada de Dados. Porto Alegre: Bookman, 2005.

HAIR JÚNIOR, J. F. Analise multivariada de dados. Porto Alegre: Bookmann,2005.

HAND, J. R. M.; LEV, B. Intangible assets: values, measures, and risks. Oxford, Inglaterra: Oxford University Press, 2003.

IENCIU, N. M.; MATIS, D. A theoretical framework of intellectual capital. International Journal of Business Research, v. 11, n. 2, p. 501-521, Mar. 2011.

KOGUT, B.; ZANDER, U. Knowledge of the firm, combinative capabilities, and the replication of technology. Organization Science, [S.I], v. 3, n. 3, p. 383-397, 1992.

LANE, P. J.; KOKA, B. R.; PATHAK, S. The reification of absorptive capacity: a critical review and rejuvenation of the construct. Academy of Management Review, [S.I], v. 31, n. 4, Oct. 2006.

LEONARD, D.; SENSIPER, S. The role of tacit knowledge in group innovation. California Management Review, [S.I], v. 40, n. 3, p. 112132, Apr.1998.

LICHTENTHALER, U.; LICHTENTHALER, E. A capability-based 
framework for open innovation: complementing absorptive capacity. Journal of Management Studies, [S.I], v. 46, n. 8, Dec . 2009.

LIU, C. L. E. Na investigation of relationship learning in cross-border buyer-supplier relationships: the role of trust. International Business Review, [S.I], v. 21, n. 3, p. 311-3277, Jun. 2012.

LÓPEZ-NICOLÁS, C.; MEROÑO-CERDÁN, A. L. Strategic knowledge management, innovation and performance. International Journal of Information Magement, [S.I], v. 31, p. 502-509, Dec. 2011.

MACHADO, R. E.; FRACASSO, E. M. A Influência dos fatores internos na capacidade absortiva e na inovação: proposta de um framework. In: SIMPÓSIO DE GESTÃO DA INOVAÇÃO TECNOLÓGICA DAANPAD, 27., 2012, Salvador. Anais... Salvador: ANPAD, 2012. p. 1-16.

MACHADO, R. E. Influência do capital intelectual na capacidade absortiva e na inovação. 2014. 123f. Tese (doutorado em administração ) - Escola de Administração, Universidade Federal Do Rio Grande Do Sul, Porto Alegre, 2014.

MALHOTRA, N. Pesquisa de marketing: uma orientação aplicada. 6. ed. Porto Alegre: Bookman, 2012.

MANUAL DE OSLO: proposta de diretrizes para coleta e interpretação de dados sobre inovação tecnológica. Brasília: FINEP; OECD, 1997.

MARCONI, M. A.; LAKATOS, E. M. Fundamentos de metodologia científica. São Paulo: Atlas, 2010.

MORGADO, R. S.; FLEURY, A. Evidências comparativas em empresas brasileiras e estrangeiras na transferência de conhecimento no franchising. Internext. Revista Eletrônica de Negócios Internacionais da ESPM, São Paulo, v. 6, n. 1, p. 84-98, jan./jun. 2011.

NODA, T.; BOWER, J. L. Strategy making as iterated resource allocation. Strategic Management Journal, [S.I], v. 17, n.51, p. 159192, Summer 1996. 
NUNNALLY, J. C.; BERNSTEIN, I. H. Psychometric theory. New York, NY: MGraw-Hill. 1994.

OLIVEIRA, S. R.; BALESTRIN, A. O desenvolvimento da capacidade absortiva em projetos tecnológicos entre universidade e empresa: um estudo de caso da cooperação unisinos - ht micron. In: ENCONTRO ANUAL DA ANPAD, 36, 2012. Rio de Janeiro. Anais..., Rio de Janeiro: EnANPAD, 2012. p. 1-16.

PRAHALAD, C. K.; HAMEL, G. The core competence of the corporation. Harvard Business Review, [S.I], v. 68, n. 3, p. 79-91, May-June 1990.

RODRIGUEZ Y RODRIGUEZ, M. Gestão Empresarial: Organizações que Aprendem. Rio de Janeiro: Qualitymark Editora Ltda., Petrobras, 2002.

SANTOS, D. F. L.; BASSO, L. F. C.; KIMURA, H. A estrutura da capacidade de inovar das empresas brasileiras: uma proposta de constructo. Revista de Administradores e Inovação, São Paulo, v. 9, n. 3, p. 103-1028, jul/set. 2012.

SCHMIDT, T. What determines absorptive capacity. In: DRUID TENTH ANNIVERSARY SUMMER CONFERENCE DYNAMICS OF INDUSTRY AND INNOVATION: ORGANIZATIONS, NETWORKS AND SYSTEMS. 2005. Copenhagen, Denmark. Anais... Copenhagen, June, 2005. p. 27-29.

SOUZA, L. A. et al. Modelo de gestão em incubadoras e mapas de desempenho. Revista Ciências da Administração, Fortaleza, v. 21, n. 1, p. 112-130, jan./jun. 2015.

STEFANO, N. et al. Gestão de Ativos Intangíveis: implicações e relações da gestão do conhecimento e capital intelectual. João Pessoa, v. 4, n. 1, p. 22-37, jan./jun. 2014.

STEWART, T. A. Capital intelectual. a nova vantagem competitiva das empresas. 2. ed. Rio de Janeiro: Ed. Campus, 1998. 


\section{STOECKICHT, I. P. Gestão estratégica do capital intelectual} orientado à inovação em empreendimentos de engenharia civil. 2012. 15f. Tese (Doutorado em Tecnologia da Construção) Universidade Federal Fluminense, Niterói-RJ, 2012.

SZULANSKI, G. Exploring internal stickiness: impediments to the transfer of best practice within the firm. Strategic Management Journal (1986-1998), Chichester, v. 17, Special Issue, p. 27-27, winter 1996.

WANG, C.; HAN, Y. Linking properties of knowledge with innovation performance: the moderate role of absorptive capacity. Journal of Knowledge Management, Kempston, v. 15, n. 5, p. 802-819, Sep. 2011.

ZAHRA, S. A.; GEORGE, G. Absorptive capacity: a review, reconceptualization, and extension. Academy of Management Review, [S.I], v. 27, n. 2, p. 185-203, Apr. 2002.

Data de Submissão: 19/11/15

Data de Aprovação: 12/15/16 